International Journal of Advanced Biological and Biomedical Research Available online at http:www.ijabbr.com

Volume 7, Issue 3 (2019) pp. 246-254

Original Article

\title{
Pretreatment of Nano Chitosan and Nano Calcium (X. gideon) in the Application of Acetic Acid to Enamel Hardness
}

\section{Ade Komariah Komariah',*, Selly Parcelia'², Bambang S. Trenggono ${ }^{1}$}

${ }^{1}$ Department of oral biology, faculty of dentistry Trisakti University, Kyai Tapa, Grogol, Jakarta Barat 1140, Indonesia

${ }^{2}$ Department of oral biology, faculty of dentistry Yarsi University, Letjend Suprapto, Central Jakarta City, 10510, Indonesia

*Corresponding Author E-mail: akomariah67@gmail.com; komariah@trisakti.ac.id

Received: March 2019, Revised: 4 May 2019, Accepted: 7 May 2019

\section{ABSTRACT}

Background: Chitosan and Calcium can be regarded as the natural polymeric materials obtained from the exoskeleton of Xylotrupes gideon through demineralization, deproteinization and deacetylation processes. Nano chitosan and calcium can inhibit the demineralization process, which is caused by the consumption of acetic acid. This study aims at determining the effect of nano chitosan pretreatment and nano calcium $X$. gideon on the application of acetic acid toward tooth enamel hardness.

Methods: The study used 36 upper teeth premolars divided into 4 groups; the first group was artificial saliva control, the second group was acetic acid application without pretreatment with nano chitosan and nano calcium, the third group was given pretreatment with nano chitosan and the fourth group was given pretreatment with nano chitosan and nano calcium (5:1).

Results: The results showed that there were significant differences in all groups both without or with nano chitosan pretreatment and combination nano chitosan and nano calcium $X$. gideon on the application of acetic acid to hardness of tooth enamel $(p<0.05)$.

Conclusions: Research using combination of nano chitosan and nano calcium proved to be more effective in inhibiting the demineralization process by increasing the hardness of tooth enamel as compared to other groups.

Key words: Nano chitosan, Nano calcium, X. Gideon, Enamel microhardness.

\section{Introduction}

The oral cavity is maintained in a healthy and balanced condition with a homeostatic mechanism, which regulates physiological conditions, such as $\mathrm{pH}$, temperature, salivary flow, viscosity, microflora etc. (Ghosh et al., 2016). Any interference with this mechanism can cause pathological conditions, which can cause various diseases affecting the soft and hard tissues in the mouth, such as teeth (Guiglia et al., 2010). 
Tooth consists of hard tissue in the form of enamel, dentine, and cementum. Enamel is the outermost tooth tissue that covers the anatomical crown of the tooth and in each area has a different thickness (Goldberg et al., 2012). Decrease enamel hardness can occur due to the contained mineral elements which have partial or overall solubility as a result of acid. This occurs due to the permeable nature of tooth enamel against molecules and ions (Wongkhanteea et al., 2005). Acid concentration, presence of calcium and phosphate ions, degree of acidity $(\mathrm{pH})$, and dissolution time are factors that affect the speed of dissolution of enamel (Sosa-Puente et al., 2014).

Demineralization of teeth is the process of losing some or all of the mineral ions in teeth (enamel), one of which is caused by acid (Abou Neel et al., 2016). The mechanism of tooth enamel solubility by acid through the consumption of food or drinks will be fermented by microorganisms which consequently increases the degree of acidity in the oral cavity (Mesquita-Guimarães et al., 2015). The oral cavity tends to be acid due to acid production by cariogenic oral bacteria from food residues, dietary acids, fruit, carbonated drinks, endogenous acids (Ehlen et al., 2008). When demineralized, dissolution of the inorganic component occurs. Demineralization can reduce dental hardness through the formation of porosity on the surface of enamel (Budak et al., 2014).

Acetic acid or so-called vinegar in daily life is widely used by the public. The use of vinegar, especially in Indonesia, is often consumed in the form of food in various regions, pickles, meatballs with the addition of kitchen vinegar, and some fruits that have a taste of vinegar and fresh tamarind. One of vinegars that is also used by the community is apple vinegar which is widely produced all over the world and possesses a concentration of acetic acid as much as $4-8 \%$. Some of the benefits of vinegar include: being used as anti-microbial, reduction of the cancer risk, brain health, weight loss, improving heart health, increasing blood sugar and insulin levels in type II diabetics (Ghosh et al., 2016). Foods that contain vinegar if consumed constantly can damage tooth enamel. Tooth enamel damage can reduce dental hardness due to continuous tooth demineralization. Reduction in calcium and phosphate ratios withloss of organic components from enamel tooth surfaces can cause tooth sensitivity (Klaric et al., 2015).

In order to be able to maintain the hardness of tooth enamel, natural ingredients are used as an alternative to prevent the decline in tooth enamel hardness caused by demineralization processes, such as the use of chitosan and calcium (Visveswaraiah et al., 2014; Raharjo et al., 2015). Chitosan and calcium can be found in horn beetles (Xylotrupes gideon) which are known to harm humans. The detrimental properties of horn beetles can be utilized as economic value materials for humans, by processing them into chitosan and calcium (Komariah et al., 2017).

Chitosan is a linear polysaccharide, composed of $\beta$-(1-4) -linked D-glucosamine and Nacetyl-D-glucosamine. Chitosan has beneficial properties such as, biocompatible, biodegradable, non-toxic, selective permeable, and very bioactive (Komariah et al., 2017). Physical modification of chitosan and calcium can increase the activity of these materials, so that it can be applied to various fields, especially its use as a medicinal ingredient in the field of dentistry (Komariah et al., 2017).

By looking at the existing problems, it is necessary to conduct research on the benefits of nano chitosan and nano calcium in preventing tooth enamel demineralization due to consumption of acetic acid, so as to increase the hardness of tooth enamel. The purpose of this study was to determine the effect of nano chitosan pretreatment, as well as the 
combination of nano chitosan and nano calcium $X$. gideon in inhibiting the demineralization of enamel before exposure to acetic acid.

\section{Materials and methods}

The used $X$. gideon came from the Cangkurawok, Damaga, Balumbang Jaya, Bogor, West Java. $X$. gideon underwent demineralization ( $\mathrm{HCl}$ 3N, Merck), deproteinization $(\mathrm{NaOH} 3 \mathrm{~N}$, Merck), decalorization $\left(\mathrm{H}_{2} \mathrm{O}_{2}\right.$, Merck) and deacetylation (50\% $\mathrm{NaOH}$, Merck). The studied dental sample was the first jaw premolar teeth on orthodontic treatment from extraction patients aged 14-18 years, with caries-free dental conditions, no fracture and cracking, 1/3 insisal flat teeth, and intact dental crowns.

\section{Nano material}

Nano calcium is obtained by precipitation method from the results of demineralization $X$. gideon (Figure 1), while nano chitosan is obtained by chitosan ionic gelation method into smaller particles. Nano chitosan and calcium are dried by spray dry. Nano chitosan and nano calcium powder is made into concentrations of $4000 \mathrm{ppm}, 6000 \mathrm{ppm}$, and $8000 \mathrm{ppm}$, while a combination of nano chitosan and nano calcium was made with a ratio of 5:1.

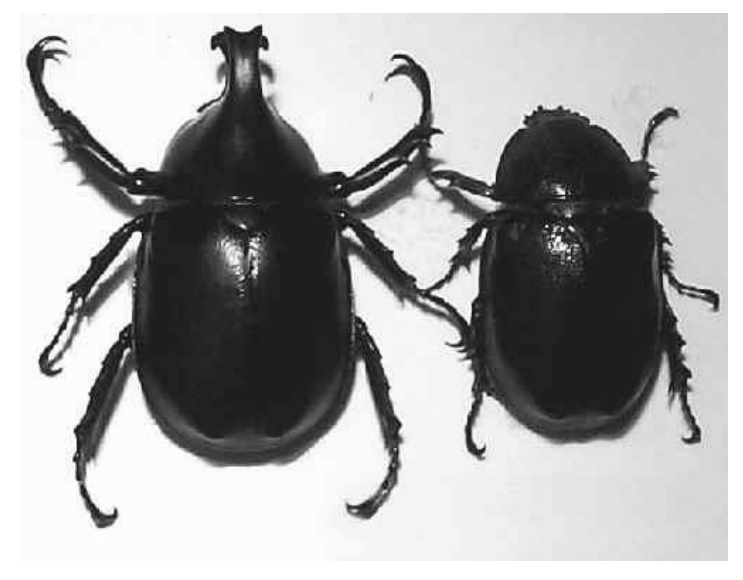

Figure 1. Xylotrupes gideon

\section{Premolar teeth pretreatment}

Samples of premolar teeth are cleansed using a toothbrush. Prior to pretreatment, samples were tested for dental hardness with Vickers Hardness Tester Leco m-400-h1 series, then the samples were grouped into four groups. The control group was only soaked with artificial saliva. The acetic acid group was immersed with artificial saliva for 6 hours, then, underwent demineralization simulation by 4\% acetic acid application for 15 minutes. The nano chitosan group was pretreated with nano chitosan solution with concentration of $4000 \mathrm{ppm}, 6000 \mathrm{ppm}$ and $8000 \mathrm{ppm}$ for 15 minutes, after that they were immersed in artificial saliva solution for 6 hours, followed by an application of 4\% acetic acid for 15 minutes. Group of nano chitosan and nano calcium was pretreated with a mixture of nano chitosan and nano calcium solutions with concentrations of 4000 ppm, 6000 ppm, and 8000 ppm (5:1) for 15 minutes, after which it was immersed in an artificial saliva solution for 6 hours, followed by demineralization simulation using 4\% acetic acid for 15 minutes. The treatments in groups were carried out once a day for 7 days. Before measuring dental 
hardness, samples were stored in artificial saliva at room temperature. The experiment was conducted according to the Human Ethics issued by the Faculty of Dentistry, University of Trisakti (Number: 121/S1/KEPK/FKG/2018).

\section{Measure of tooth enamel hardness}

All the samples that were tested for dental hardness were also mounted using a resin and catalyst solution (100 mL: $1 \mathrm{~mL}$ ) and, then, let sit until they hardened. Vickers Hardness test (Leco seri m-400-h1, USA) was carried out on one indent part of the middle of the buccal surface of the tooth enamel. The form of the produced indentation was observed through a microscope lens with $400 \mathrm{X}$ magnification so that the rhombus shape would appear.

\section{Statistic analysis}

The obtained data from the results of the study were analyzed using SPSS 23.0 for Windows. If normal data distribution is carried out by One-way Anova test, a significant (meaningful) result is obtained, then Bonferroni Post-hoc analysis is performed. Test results, before and after treatment, were carried out using the T-Test.

\section{Results and discussion}

One-way ANOVA test results showed significant differences $(p<0.05)$ in all treatment groups. Artificial salivary control group as a negative control with mean tooth enamel hardness of $19.54 \pm 1.86 \mathrm{HVN}$, acetic acid group as a positive control with mean enamel hardness of $8.20 \pm 1.35 \mathrm{HVN}$, group given nano chitosan pretreatment with mean enamel hardness of $32.31 \pm 11.53 \mathrm{HVN}$, and the group given a pretreatment combination of nano chitosan and nano calcium with a mean value of tooth enamel hardness of $46.24 \pm 12.73$ HVN have been illustrated in Figure 2.

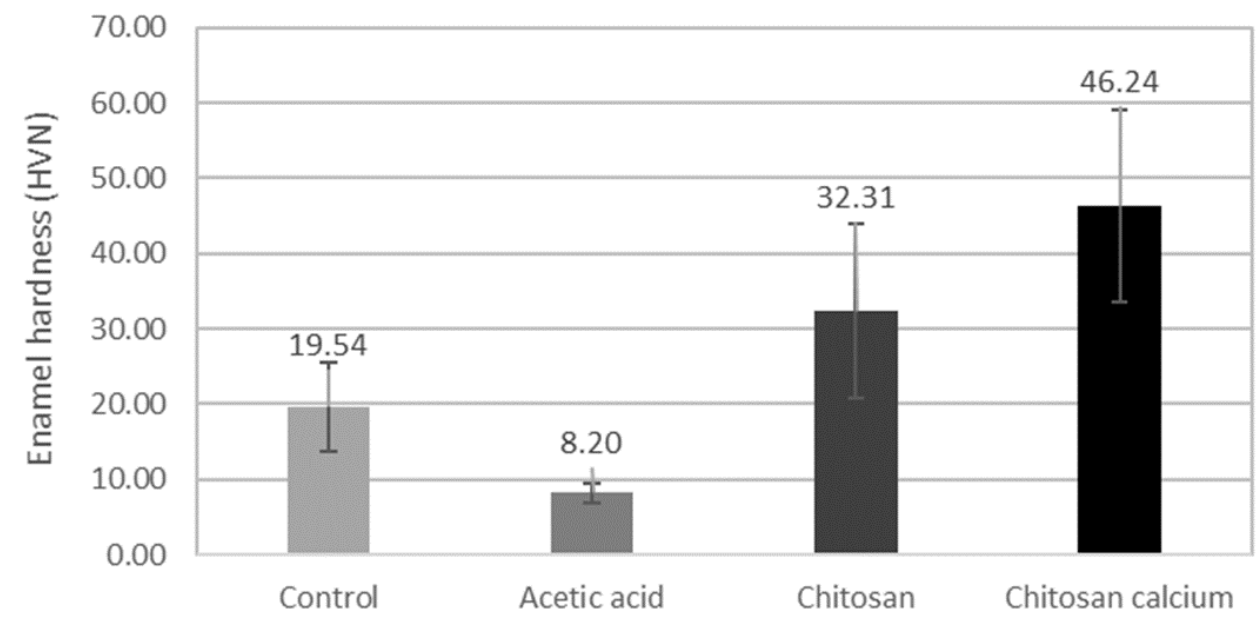

Figure 2. Hardness of tooth enamel in the treatment group

A decreasing hardness of enamel in the group given acetic acid has been compared to the saliva group. This suggested that there was a decreasing of hardness in acetic acid group as compared to control. In this sense, the group given pretreatment with nano chitosan showed no significant differences ( $p>0.05)$ as compared to the mixture of nano chitosan 
and nano calcium pretreatment. On the contrary, the pretreatment with a mixture of nano chitosan and nano calcium showed a higher average mean value of $43.11 \%$ as compared to nano chitosan without the addition of nano calcium (Table 1).

Table 1. Before and after for all treatment group

\begin{tabular}{cccc}
\hline Group & \multicolumn{2}{c}{$\begin{array}{c}\text { Before } \\
(\text { Mean } \pm \text { Sd) }\end{array}$} & After \\
\hline Control & $390.83 \pm 31.70$ & $410.37 \pm 31.99$ & \\
Acetic acid & $408.71 \pm 31.99$ & $416.91 \pm 31.56$ & 0.00 \\
Nano Chitosan & $441.39 \pm 48.42$ & $473.69 \pm 51.69$ & 0 \\
Nano Chitosan Calcium & $429.02 \pm 48.84$ & $475.26 \pm 55.33$ & \\
\hline
\end{tabular}

The average results of differences of dental hardness in groups given nano chitosan concentrations of 4000, 6000, and 8000 ppm before being given acetic acid showed significant differences $(\mathrm{p}<0.05)$. The results of hardness enamel of dental pretreatment with nano chitosan 4000 ppm were not significantly different ( $p>0.05)$ as compared to the saliva artifisial group, but the value of dental hardness was higher than the group given acetic acid without pretreatment with nano chitosan $(\mathrm{p}<0.05)$. Whereas dental hardness in the pretreatment group with nano chitosan 6000 ppm and 8000 ppm was significantly different with $\mathrm{p}$ value $<0.05$, pretreatment of nano chitosan $8000 \mathrm{ppm}$ was able to increase the value of dental hardness by $52.29 \%$ as compared to pretreatment with nano chitosan 6000ppm (Figure 3).

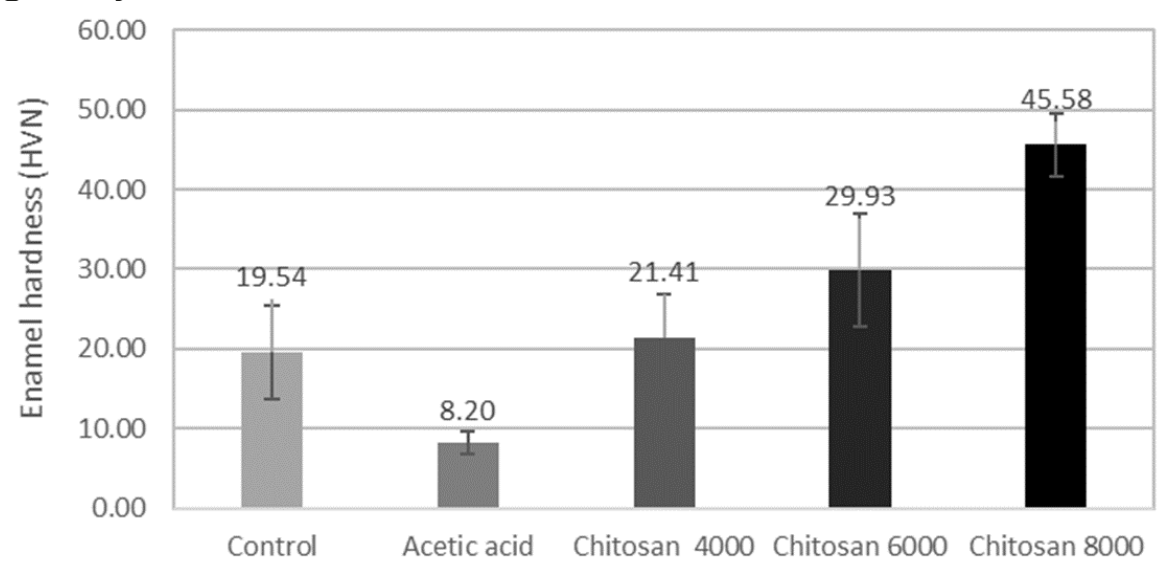

Figure 3. Enamel hardness in nano chitosan pretreatment

The results of the $t$-test before and after the control group given artificial saliva showed an increase of $4.99 \%$. In the group of teeth given acetic acid without nano chitosan pretreatment, there was an increase up to $2.00 \%$ which was lower than the control $(\mathrm{p}<0.05)$. Meanwhile, the group pretreated with nano chitosan 4000, 6000 and $8000 \mathrm{ppm}$ showed an increasing value after pretreatment as compared to the previous treatment with a value of $\mathrm{p}<0.05$. The increased enamel hardness in this group can be stated as $4.92 \%$, $6.98 \%$, and $9.88 \%$ respectively. In this regard, it showed that the higher the concentration of nano chitosan used at pretreatment the higher the ability is to inhibit the demineralization by increasing the hardness of enamel in the pretreatment group given nano chitosan (Table 2). 
Table 2. Before and after nano chitosan pretreatment

\begin{tabular}{|c|c|c|c|}
\hline Group & $($ Mean $\pm S d)$ & After & $p$ \\
\hline Control & $390.83 \pm 31.70$ & $410.37 \pm 31.99$ & \\
\hline Acetic acid & $408.71 \pm 31.99$ & $416.91 \pm 31.56$ & 0.000 \\
\hline Nano Chitosan 4000 & $434,49 \pm 19,76$ & $455,90 \pm 19,84$ & \\
\hline Nano Chitosan 6000 & $428,45 \pm 35,81$ & $458,39 \pm 35,22$ & \\
\hline Nano Chitosan 8000 & $461,22 \pm 72,10$ & $506,80 \pm 35,22$ & \\
\hline
\end{tabular}

The ANOVA test from the results of a mixture of nano chitosan and nano calcium at concentrations of 4000, 6000 and 8000 ppm showed artificial saliva control group with an average value of $19.54 \pm 1.86 \mathrm{HVN}$, acetic acid group as a positive control with the mean value of enamel hardness of $8.20 \pm 1.35 \mathrm{HVN}$. Whereas in the pretreatment group with a mixture of nano chitosan and nano calcium 4000, 6000, and $8000 \mathrm{ppm}$ increased the hardness with $p$ value $<0.05$ of with mean result $37.67 \pm 9.70,43.38 \pm 10.45$, and $57.68 \pm 9.17$ HVN respectively (Figure 4).

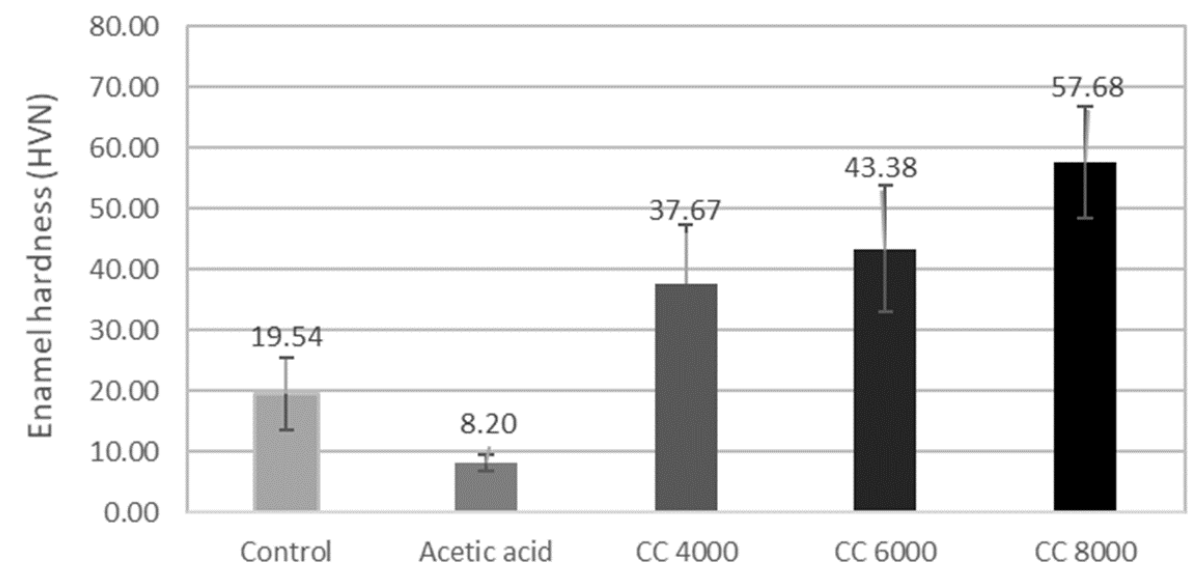

Figure 4. Hardness of tooth enamel in nano chitosan calcium pretreatment

The combination of nano chitosan and nano calcium at concentrations of 4000, 6000 and $8000 \mathrm{ppm}$ was significantly different with $\mathrm{p}$ value $<0.05$ as compared to the control group. A combination of nano chitosan and nano calcium at the concentrations of $4000 \mathrm{ppm}$ and $6000 \mathrm{ppm}$ was not significantly different $(\mathrm{p}>0.05)$, but had a lower enamel hardness value as compared to the concentration of $8000 \mathrm{ppm}$.

Table 3. Before and after treatment nano chitosan calcium

\begin{tabular}{cccc}
\hline Group & Before & After & $\boldsymbol{p}$ \\
& \multicolumn{2}{c}{$($ Mean \pm Sd) } & \\
\hline Control & $390.83 \pm 31.70$ & $410.37 \pm 31.99$ & \\
Acetic acid & $408.71 \pm 31.99$ & $416.91 \pm 31.56$ & 0.000 \\
Nano CC 4000 & $415.32 \pm 22.63$ & $452.989 \pm 23.12$ & \\
Nano CC 6000 & $410.52 \pm 27.41$ & $453.900 \pm 30.41$ & \\
Nano CC 8000 & $461.21 \pm 68.77$ & $518.889 \pm 72.66$ & \\
\hline
\end{tabular}




\section{Discussion}

In the presented study, the use of acetic acid has been analyzed by looking at the lifestyle of people who use acetic acid for consumption. The form of acetic acid commonly used in foods such as vinegar from fruits, rice vinegar, and kitchen vinegar has a composition of acetic acid of 15\%-29\% (Cortesia et al., 2014).

Chitosan has a long-term effect after administration, this gives its own advantages to chitosan in preventing demineralization. Nano-complex chitosan calcium can remineralize enamel surfaces at a significantly higher level than fluoride administration (Abou Neel et al., 2016). Chitosan can act as a mechanical barrier to acid penetration in enamel and inhibit the demineralization process through inhibition of mineral element release,(Arnaud et al., 2010) this is due to the fact that chitosan has an organic component that can inhibit the rate of breakdown by acid in hydroxyapatite (Lee et al., 2012). Chitosan organic compounds are free amine groups (NH2) which are able to reduce acid and increase $\mathrm{pH}$, because chitosan is very reactive to acids (Changa et al., 2012). Cross-linking that occurs between chitosan and saliva by physical adsorption of chitosan to saliva and cross-linking that occurs between chitosan and tooth enamel allows chitosan to prevent acid erosion on the surface of hydroxyapatite (Visveswaraiah and Prasad, 2016).

Generally, in the no pretreatment group, artificial salivary and acetic acid control group, as well as nano chitosan pretreatment group and combination of nano chitosan and nano calcium showed significant differences, but in the mixture group of nano chitosan and nano calcium we witnessed a higher effect on enamel hardness as compared to other groups. The results of this study are supported by previous studies which stated that enamel surface hardness with application of chitosan had higher enamel hardness in Vickers Hardness test (Visveswaraiah et al., 2014) whereas with the addition of nano calcium we witnessed an increased dental hardness as compared to the absence nano calcium. This shows that the nano particles with small particle size are able to fill the enamel pores that are demineralized so as to increase the hardness and strength of the teeth (Priyadarsini et al., 2017).

In the artificial saliva and acetic acid control group, dental hardness is increased, but not as high as those in the presence of nano chitosan and calcium pretreatment. This is because of the fact that saliva itself can affect the remineralization of enamel (Hegde and Sajnani, 2017). This is proven by the value of dental hardness in the group given acetic acid which was also increased, but not as high as the saliva group.

\section{Conclusion}

Pretreatment of nano chitosan and nano calcium can prevent demineralization of tooth enamel, so as to increase dental hardness after application or administration of acetic acid.

\section{Acknowledgements}

I would like to offer my special thanks to laboratory assistant of engineering faculty Institute Technology Bandung in helping to measurement the tooth hardness test

\section{References}

Abou Neel, EA, Aljabo, A, Strange, A, Ibrahim, S, Coathup, M, Young, AM, Bozec, L, Mudera, V. 
(2016). Demineralization-remineralization dynamics in teeth and bone. Int. J. Nanomedicine, 6:4743-47.

Arnaud, TMS, De Barros Neto, B, Diniz, FB. (2010). Chitosan effect on dental enamel deremineralization: An in vitro evaluation. J. dent., 38:848-52.

Budak, NH, Aykin, E, Seydim AC, Greene, KA, Guzel-sydim, ZB. (2014). Functional properties of vinegar. J. Food Sci., 79:757-64.

Changa, J, Chena, C, Ellis, AV, Tung, CH. (2012). Studies of chitosan at different ph's in the removal of common chlorinated organics from wastewater. Int. J. Appl. Sci. Eng., 10:293306.

Cortesia, C, Vilchèze, C, Bernut, A, Contreras, W, Gómez, K, De Waard, J, Jacobs, WR, Kremer, L, Takiffa, H. (2014). Acetic acid, the active component of vinegar, is an effective tuberculocidal disinfectant. Am. Soc. Microbiol., 5:1-4.

Ehlen, LA, Marshall, TA, Qian, F, Wefel, JS, Warren, JJ. (2008). 'Acidic beverages increase the risk of in vitro tooth erosion. Nutr. Res., 28:299-303.

Ghosh, A, Pallavi, SK, Nagpal, B. (2016). Nutrition and oral health, Lambert Academic Publishing, Deutschland, Germany, pp 6-73.

Goldberg, M, Kulkarni, AB, Young, M, Boskey, A. (2012). Dentin: Structure, composition and mineralization: The role of dentin ECM in dentin formation and mineralization. Front Biosci, 3:711-35.

Guiglia, R, Musciotto, A, Compilato, D, Procaccini, M, Lo Russo, L, Ciavarella, D, Lo Muzio, L, Cannone, V, Pepe, I, D'Angelo, M, Campisi, G. (2010). Aging and oralhHealth: Effects in hard and soft tissues. Curr. Pharm. Des., 16:619-30.

Hegde, MN, Sajnani, AR. (2017). Salivary proteins-A Barrier on enamel demineralization: An in vitro study. Int. J. Clin. Pediatr Dent., 10:10-13.

Klaric, E, Rakic, M, Sever, I, Milat, O, Par, M, Tarle, Z. (2015). Enamel and dentin microhardness and chemical composition after experimental light-activated bleaching. Oper Dent., 40:132-41.

Komariah, A, Laksono, WA, Bustami, DA, Trenggono, BS. (2017). Effects Chitosan and Calcium Nanoparticles Mouthwash from Xylotrophes gideon In the Liver And Kidney Rat. Res. J. Pharm. Biol. Chem. Sci., 8:1-9.

Komariah, A, Tatara, RA, Bustami, DA. (2017). Efficacy of Rhinoceros Beetle (Xylotrupes gideon) nano chitosan and calcium mouthwash in reducing quantity oral cavity bacteria among elementary school age children. Int. J. Adv. Biol. Biomed. Res., 5: 41-7.

Lee, H, Tsai S, Kuo, C, Bassania, AW, Pepe-Mooney, B, Miksa, D, Masters, J, Sullivan, R, Composto, RJ. (2012). Chitosan adsorption on hydroxyapatite and its role in preventing acid erosion. J. Coll. Interface Sci., 385:235-43. 
Mesquita-Guimarães, KS, Scatena, C, Borsatto, MC, Rodrigues-Júnior, AL, Serra, MC. (2015). Effect of foods and drinks on primary tooth enamel after erosive challenge with hydrochloric acid. Bra. Oral Res., 29:1-7.

Priyadarsini, S, Mukherjee, S, Mishra, M. (2017). Nanoparticles used in dentistry: A review. JOBCR. Pp. 1-12.

Rahardjo, A, Nugraheni, DDT, Humaira, G, Adiatman, M, Maharani, DA. (2015). Efficacy of toothpaste containing nano calcium in dentin remineralization. Makara J. Health Res., 19:437.

Sosa-Puente, C, Solís-Soto, J, Cruz-Fierro, N, López-Villarreal, S, Nakagoshi-Cepeda, S. (2014) Dental erosion: causes, diagnostics and treatment. J. Oral Res., 3:257-61.

Visveswaraiah, PM, Prasad, D, Johnson, S. (2014). Chitosan A novel way to intervene in enamel demineralization; An in vitro study. Int. J. Curr. Microbiol. App. Sci., 3:617-67.

Visveswaraiah, PM, Prasad, D. (2016). Effect of water soluble carboxymethyl chitosan and chitosan lactate on enamel demineralisation- an sem study. Res. J. Pharm. Biol. Chem. Sci., 7:427-33.

Wongkhantee, S, Patanapiradej, V, Maneenut, C, Tantbirojn D. (2006). Effect of acidic food and drinks on surface hardness of enamel, dentine, and tooth-coloured filling materials. $J$. dent., 34:214-20.

How to cite this article: Ade Komariah Komariah, Selly Parcelia, Bambang S. Trenggono, Pretreatment of Nano Chitosan and Nano Calcium (X. gideon) in the Application of Acetic Acid to Enamel Hardness. International Journal of Advanced Biological and Biomedical Research, 2019, 7(3), 246-254. Link: http://www.ijabbr.com/article 35123.html 